\title{
Proposta de implantação da ferramenta Balanced Scorecard em uma empresa de pequeno porte
}

A administração estratégica, dentro de uma organização, consiste em um processo de análise da empresa sob diversos ângulos, em um direcionamento de rumos e monitoramento das ações. Além disso, é formada por um processo contínuo, desde a análise do ambiente empresarial até o controle estratégico. Dispondo de ferramentas de suporte à gestão estratégica, como o Balanced Scorecard (BSC), a administração estratégica auxilia no alinhamento entre a dinâmica do ambiente em que a organização está inserida e na definição de objetivos, estratégias e ações, bem como no controle dos resultados. Assim, se bem utilizada pela empresa, ela é capaz de fornecer uma série de benefícios. Diante disso, o presente trabalho visa à implantação da ferramenta Balanced Scorecard em uma empresa do ramo de consultoria empresarial, contemplando a elaboração de algumas etapas do seu planejamento estratégico. Para tanto, foi realizada uma pesquisa de natureza descritiva com abordagem metodológica qualitativa, optando-se pelo estudo de caso, devido à ênfase em uma unidade de estudo em particular. A partir de uma revisão bibliográfica, pesquisa documental, entrevista semiestruturada com os proprietários e observação participante, foi possível realizar a estruturação e organização do BSC, permitindo determinar os caminhos que irão nortear a implementação de algumas etapas do planejamento estratégico, para posterior alcance dos objetivos e resultados pretendidos.

Palavras-chave: Administração estratégica; Ferramenta de gestão; Balanced Scorecard.

\section{Proposal to implement the Balanced Scorecard tool in a small company}

\begin{abstract}
Strategic management, within an organization, consists of a process of analysis of the company from various angles, a direction of direction and monitoring of actions. In addition, it is formed by a continuous process, from the analysis of the business environment to the strategic control. With strategic management support tools such as the Balanced Scorecard (BSC), strategic management helps align the dynamics of the organization's environment and define objectives, strategies and actions, as well as the control of results. Thus, if well used by the company, it is able to provide a number of benefits. Therefore, the present work aims at the implementation of the Balanced Scorecard tool in a business consulting business, contemplating the elaboration of some stages of its strategic planning. For this, a descriptive research with qualitative methodological approach was carried out, opting for the case study, due to the emphasis on a particular unit of study. From a bibliographic review, documentary research, semi-structured interview with the owners and participant observation, it was possible to carry out the structuring and organization of the BSC, allowing to determine the paths that will guide the implementation of some stages of the strategic planning, for later reaching the objectives and intended results.
\end{abstract}

Keywords: Administração estratégica; Ferramenta de gestão; Balanced Scorecard.

Topic: Planejamento, Estratégia e Competitividade

Reviewed anonymously in the process of blind peer.

Laís Viera Trevisan

Universidade Federal de Santa Maria, Brasil

http://lattes.cnpq.br/0833905079327471

laisvtrevisan@gmail.com

Camila Borges Fialho

Universidade Federal de Santa Maria, Brasil

http://lattes.cnpq.br/4167579847277378

ca.fialho@yahoo.com.br

Daniel Arruda Coronel

Universidade Federal de Santa Maria, Brasil

http://lattes.cnpq.br/9265604274170933

daniel.coronel@uol.com.br

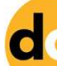

DOI: 10.6008/CBPC2179-684X.2018.002.0007
Received: 02/06/2018

Approved: 03/08/2018
Referencing this:

TREVISAN, L. V.; FIALHO, C. B.; CORONEL, D. A.. Proposta de implantação da ferramenta Balanced Scorecard em uma empresa de pequeno porte. Revista Brasileira de Administração Científica, v.9, n.2, p.76-89, 2018. DOI: http://doi.org/10.6008/CBPC2179$\underline{684 X .2018 .002 .0007}$ 


\section{INTRODUÇÃO}

No atual cenário empresarial, extremamente competitivo, as organizações necessitam dar a devida importância ao conhecimento e ao aprendizado contínuo a fim de entregar as propostas de valor requeridas pelos clientes para, só assim, sobreviver no mercado. Isso faz com que as empresas busquem alternativas para se adaptarem às mudanças do ambiente, diferenciarem-se da concorrência, o que implica repensar suas estratégias. Neste contexto, uma maneira de alcançar estas demandas é a prática da administração estratégica.

Para Certo et al. (2010), a administração estratégica é definida como um processo contínuo e interativo que visa manter uma organização como um conjunto apropriadamente integrado a seu ambiente. Ela envolve um processo ou uma série de etapas: análise do ambiente, estabelecimento de diretrizes organizacionais, formulação de estratégias organizacionais, implementação das estratégias e controle estratégico. Com o propósito de auxiliar nos seus processos, a administração estratégica dispõe de algumas ferramentas, entre elas o Balanced Scorecard (BSC). Essa foi apresentada por Kaplan et al. (1992) e permite assessorar a implementação das estratégias organizacionais, bem como a mensuração dos resultados obtidos por elas, facilitando o acompanhamento do desempenho empresarial. Além de indicadores financeiros, o BSC contempla indicadores não financeiros que medem o desempenho da organização em suas atividades críticas.

Neste sentido, esse artigo desenvolveu-se a fim de implantar a ferramenta Balanced Scorecard em uma empresa do ramo de consultorias e capacitações. Visto que o trabalho possui informações confidenciais a respeito da empresa, por questões de sigilo, neste estudo ela será denominada 'Alpha'. Com origem na cidade de Santa Maria (RS), no momento, passa por um processo de expansão de mercado e de carteira de clientes, abrangendo também a cidade São Luiz Gonzaga (RS) e Região Central do estado. Em função disso, vem experimentando uma necessidade de reformular algumas áreas e atividades.

Assim, por meio de técnicas de coleta de dados como a revisão bibliográfica, a pesquisa documental, a entrevista semiestruturada e a observação participante, o objetivo deste estudo foi colocar à disposição da Alpha um conjunto de objetivos, estratégias e ações, bem como indicadores de desempenho e planos de ação, capazes de retratar o resultado de suas atividades, servindo de fonte de informações para a tomada de decisões dos gestores. $\mathrm{O}$ artigo está estruturado em seis seções. Nesta primeira seção, apresenta-se a introdução; na segunda, encontra-se o referencial teórico acerca da administração estratégica e da ferramenta Balanced Scorecard. Logo, na terceira seção, é feita a apresentação da empresa Alpha; na quarta, encontra-se o método utilizado para o desenvolvimento do trabalho. A implantação da ferramenta é exposta na seção cinco e, por último, na seção seis, é apresentada a conclusão do estudo.

\section{REVISÃO TEÓRICA}

\section{O conceito de administração estratégica}


De acordo com Certo et al. (2010), a administração estratégica é o processo contínuo e circular que tem como objetivo manter a organização integrada ao seu ambiente. Dessa forma, sendo seu processo circular, inicia em uma primeira etapa até a conclusão da última e então retorna à primeira, consistindo, portanto, em uma série de etapas que são repetidas ciclicamente. Aaker (2007) afirma que a administração estratégica é um sistema projetado para ajudar a determinar e tomar decisões estratégicas, bem como a criar visões estratégicas (uma visão de uma estratégia futura ou de um conjunto de estratégias).

Alguns benefícios que as organizações podem obter na implementação de um sistema de administração estratégica, citados por Certo et al. (2010), são beneficiar-se financeiramente, levar os membros da organização a se comprometerem com metas organizacionais, diminuir a probabilidade de que ela seja surpreendida por movimentos de mercado ou por ações de seus concorrentes, facilitar a identificação e a exploração de futuras oportunidades de mercado, permitir que os administradores tenham uma visão clara do negócio, etc.. Nesse sentido, Certo et al. (2010) apresenta um modelo de processo de administração estratégica, baseado em cinco etapas: análise do ambiente; estabelecimento das diretrizes organizacionais; formulação de estratégias; implementação de estratégias; e controle estratégico. A figura 1 ilustra o processo.

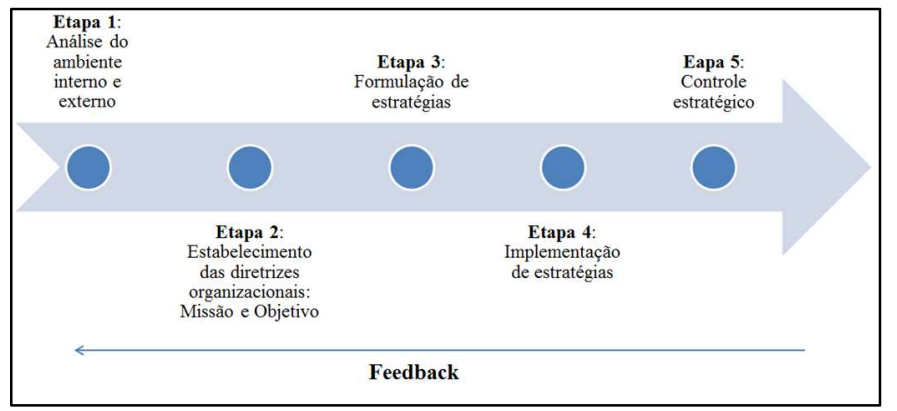

Figura 1: Principais etapas do processo de administração estratégica. Fonte: Certo et al. (2010).

Em relação à estratégia, Mintzberg (2004) afirma que estratégia é um plano, uma direção, um guia para o futuro; estratégia é um padrão: ou seja, é uma consistência em comportamento ao longo do tempo; estratégia é posição: definição de determinados produtos em determinados mercados; e estratégia é perspectiva: a maneira de a organização fazer as coisas, de acordo com seu conceito de negócio. Acerca da formulação de estratégias, Tavares (2007) afirma que é necessária uma rigorosa avaliação dos ambientes externos e internos da organização, buscando explorar as oportunidades e minimizar as ameaças, bem como explorar as potencialidades e aptidões e buscar neutralizar as fraquezas.

Segundo Aaker (2007), a escolha das estratégias deve ser baseada nos seguintes critérios: considerar os cenários ambientais da empresa; gerir um bom retorno sobre o investimento; envolver uma vantagem competitiva sustentável; ser consistente com a visão e os objetivos organizacionais; ser viável; ser consistente com outras estratégias da organização; e ser factíveis do ponto de vista organizacional.

De acordo com Certo et al. (2010), para atingir seus objetivos, uma organização deve não somente formular, mas também implementar efetivamente suas estratégias. Assim, a etapa de implementação das estratégias tem como objetivo traduzir a estratégia organizacional em ações, ou seja, deve pôr em ação estratégias que emergiram de etapas anteriores dentro do processo de administração estratégica. Para 
Oliveira (2012), a implantação de uma estratégia corresponde a, por exemplo, um novo produto/serviço, cliente ou tecnologia, e exige alterações internas na empresa, como na estrutura organizacional, no sistema de informações e na estrutura dos recursos.

Por fim, no que tange ao controle estratégico, segundo Certo et al. (2010), em uma organização, controlar significa monitorar, avaliar e melhorar as diversas atividades, também é fazer com que alguma coisa ocorra da forma como foi planejada. Portanto, a finalidade mais importante do controle estratégico é ajudar a alta administração a atingir as metas organizacionais, monitorando e avaliando a efetividade do processo de administração estratégica e controlando as estratégias de modo que elas ocorram conforme o planejado.

Nesse contexto, insere-se o conceito de desempenho organizacional, o qual é mensurado dentro da empresa por meio do controle estratégico. De acordo com Barney (1991), o desempenho empresarial representa uma percepção geral sobre os resultados da firma, que resulta da comparação entre o valor gerado por uma organização, utilizando dado capital, com o valor que os proprietários desse capital esperam obter.

Carneiro (2005) destaca que não é possível descrever o desempenho de uma empresa fazendo uso de uma única métrica, já que diversas perspectivas deverão ser consideradas para verificar se a empresa está alcançando o sucesso. Assim, cada estudo específico deverá selecionar um subconjunto de dimensões e indicadores de desempenho organizacional. Para Costa (2007), um bom planejamento estratégico não estará completo se não estiverem prontos os planos de ação. Tais planos auxiliam os gestores na visualização dos seus objetivos, metas, indicadores, prazos, entre outros aspectos. Assim, para cada objetivo, deve haver planos de ação específicos a fim de assegurar que as ações e os passos necessários para a implementação das estratégias sejam executados e acompanhados.

Segundo Andrade (2012), os planos de ação ocupam-se com questões táticas e operacionais, voltadas para o médio e curto prazo, e desdobram as decisões em planos mais detalhados e concretos. Assim, cada um dos objetivos estratégicos deve ser desdobrado a fim de serem entendidos e executados dentro de uma linguagem mais detalhada e específica, a partir da definição de: indicadores; metas; estratégias de ação; responsável pelas ações; prazo para o cumprimento de ações; e recursos financeiros necessários ao desenvolvimento de cada uma das ações.

Conforme esboçado até aqui, a administração estratégica busca obter as informações necessárias para interpretar o ambiente organizacional da empresa e fornecer aos gestores os subsídios necessários para a formulação de estratégias. Entretanto, tão importante quanto a formulação de estratégias é a implementação e o controle, quando as estratégias devem ser traduzidas em forma de metas e controladas para que os objetivos possam ser alcançados. Neste sentido, será apresentada, a seguir, a ferramenta utilizada neste estudo para alcançar tais fins.

\section{Balanced Scorecard}

Existem inúmeras ferramentas para controlar e avaliar/medir se as estratégias implantadas em uma organização estão surtindo os efeitos desejados. Uma das formas para realizar tais análises é a utilização da 
técnica Balanced Scorecard (QUEIROZ et al., 2015). O termo Balanced Scorecard, na língua portuguesa, significa 'indicadores de desempenho balanceados' e foi criado por Kaplan et al., em 1992, professores da Harvard Business School.

Tais estudiosos, motivados pela crença de que os métodos existentes, somente baseados em indicadores financeiros e contábeis, estavam tornando-se obsoletos e de que estavam prejudicando a capacidade das empresas de criar valor econômico para o futuro, deram início a um projeto de um novo modelo de medição de desempenho empresarial. Assim, o estudo deu origem ao Balanced Scorecard (BSC), um sistema que considera não apenas indicadores financeiros, mas também não financeiros oriundos da estratégia da organização. Seu grande diferencial em relação aos demais sistemas gerenciais é a capacidade de comunicar a visão e a estratégia da empresa por meio de indicadores de desempenho oriundos dos objetivos estratégicos e metas que interagem em uma estrutura lógica de causa e efeito (KAPLAN et al., 1997).

Para Tavares (2007), o BSC permite às organizações visualizarem com maior precisão como as estratégias estão contribuindo para o resultado financeiro da organização, assim como se os segmentos escolhidos são a melhor escolha, se o ambiente interno está sendo propício para atrair e reter talentos e se a inovação está contribuindo para o posicionamento estratégico da organização.

\section{As quatro perspectivas do BSC}

O BSC busca o equilíbrio entre os objetivos de curto e longo prazo, entre medidas financeiras e não financeiras, entre indicadores de tendências e ocorrências e entre as perspectivas interna e externa de desempenho. Desse modo, os autores desenvolveram indicadores de desempenho contemplando medidas voltadas para o exterior e para o interior da organização. Assim, foram estruturadas as quatro perspectivas, conforme a figura 2: financeira, clientes (voltadas para o exterior) e processos internos e aprendizado e crescimento (dirigidas para o interior).

As quatro perspectivas podem ser descritas da seguinte forma: Perspectiva financeira: mostra os resultados econômicos obtidos por meio da estratégia elaborada pela empresa, ou seja, verifica a lucratividade alcançada através do planejamento estratégico (QUEIROZ et al., 2015). As metas financeiras se relacionam com rentabilidade, crescimento e valor para os acionistas (PRIETO et al., 2006); Perspectiva do cliente: permite que as organizações identifiquem os segmentos de clientes e mercados nos quais desejam competir. De acordo com Queiroz et al. (2015), algumas medidas essenciais são satisfação do cliente, retenção de clientes, aquisição de novos clientes, lucratividade dos clientes.

Perspectiva dos processos internos: para Tavares (2007), essa perspectiva identifica as atividades necessárias para um aumento da receita com produtos atuais ou novos, em mercados atuais ou novos. Segundo Kaplan et al. (2004), na perspectiva de processos internos, as organizações identificam procedimentos que impactam significativamente a estratégia, como inovações, investimentos em laboratório de pesquisa e desenvolvimento, novos métodos de produção, criação de produtos, entre outros. 
Os processos devem criar condições para oferecer propostas de valor, atrair e reter os clientes, criando valor aos acionistas.

Perspectiva do aprendizado e do crescimento: de acordo com Queiroz et al. (2015), essa perspectiva está relacionada aos colaboradores e ao aprimoramento da gestão interna por meio de práticas gerenciais e utilização da tecnologia da informação. Para Prieto et al. (2006), a capacitação da organização é feita através de investimentos em novos equipamentos, em pesquisa e desenvolvimento de novos produtos, em sistemas e procedimentos e nos recursos humanos.

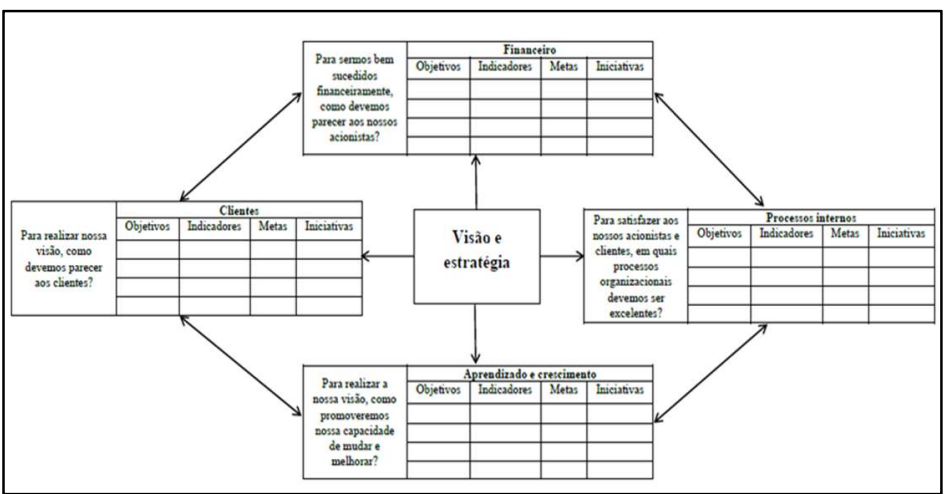

Figura 2: Tradução da visão e estratégia: as quatro perspectivas do BSC. Fonte: Kaplan et al. (1993).

Em relação à implementação do BSC, Alvarez (2011) observa que o sistema utiliza alguns componentes que auxiliam na definição e no acompanhamento dos indicadores: mapa estratégico: o mapa descreve a estratégia empresarial utilizando objetivos inter-relacionados nas quatro perspectivas; objetivo estratégico: especifica o que deve ser atingido; indicador: o indicador é como será medido o atingimento do objetivo; meta: é a taxa de melhoria esperada; e plano de ação: especifica as ações necessárias para atingir os objetivos indicados.

\section{Mapas estratégicos}

Com a finalidade de auxiliar as organizações na visualização de seus objetivos estratégicos, Kaplan e Norton desenvolveram os mapas estratégicos. Esses mapas, através de relações de causa e efeito dos objetivos, fornecem uma descrição das estratégias da empresa de forma prática e visual, facilitando as definições e o gerenciamento dos objetivos e indicadores. No mapa estratégico (figura 3), as quatro perspectivas (financeira, do cliente, interna e de aprendizado e crescimento) são conectadas uma com as outras por relações de causa e efeito. Assim, há uma hierarquização dos objetivos organizacionais, sendo que o aprendizado e o crescimento geram resultados que, por meio de melhores processos internos, permitem à organização atender seus clientes com maior eficácia, alavancando, assim, os seus resultados financeiros. Kaplan et al. (2004) descreve o mapa estratégico como 'o pilar para a construção do Balanced Scorecard'.

Nesse contexto, na visão de Corrêa Igarashi et al. (2010), o mapa ajuda as organizações a traçarem suas estratégias de maneira integrada e sistemática, servindo como alicerce para o sistema gerencial. Para isso, além do desdobramento das perspectivas, faz-se necessário disponibilizar informações que auxiliem neste processo, o que é feito através da construção de um painel de desempenho (plano de ação), do qual 
constam as perspectivas, os objetivos estratégicos, os indicadores de desempenho, as metas e as iniciativas sugeridas para o alcance das metas.

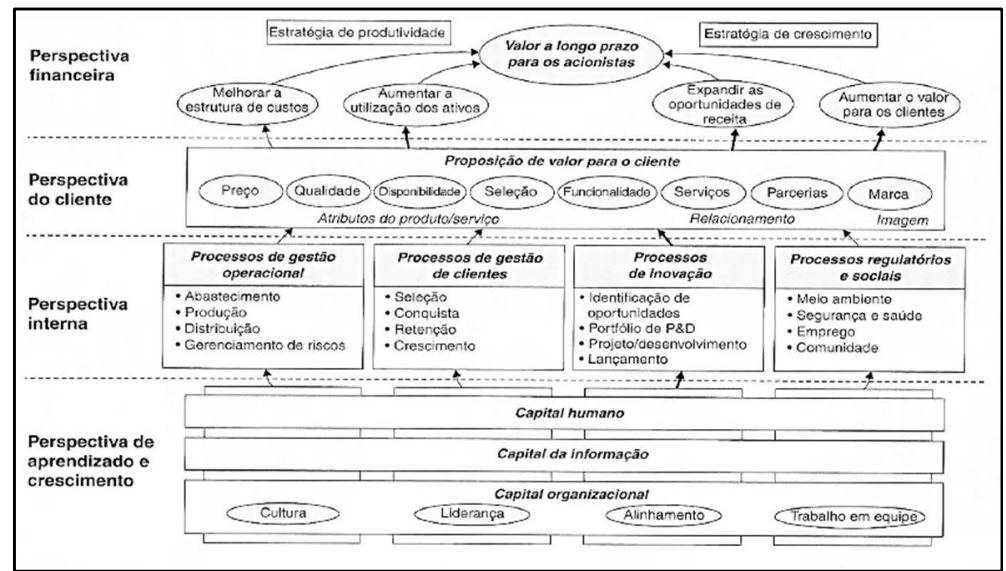

Figura 3: Mapa estratégico do BSC. Fonte: Kaplan et al. (2004).

Assim, o mapa estratégico permite uma representação visual dos objetivos da empresa, enquanto o plano de ação gerencia o desempenho da organização em cada um dos indicadores selecionados e acompanha se as metas estabelecidas estão sendo atingidas. $O$ uso integrado dessas ferramentas auxilia na visualização de seus objetivos e acompanhamento de seu desempenho empresarial, possibilitando vantagens competitivas às organizações. Na próxima seção, é apresentada a empresa objeto de estudo, seu histórico e características relevantes.

\section{Apresentação da empresa}

Salienta-se que, por questões de sigilo, a empresa em análise é denominada empresa Alpha. A Alpha é uma microempresa que atua no ramo de consultorias e capacitações e foi fundada no ano de 2015 . Através de uma pesquisa e observação do mercado da cidade de Santa Maria (RS) e região, os proprietários da Alpha constataram a oportunidade e espaço de atuação para atividades de consultoria em gestão empresarial. Com o desejo de colocar à disposição esse tipo de serviço, eles deram origem à empresa. Atualmente, ela está em processo de expansão para a cidade de São Luiz Gonzaga (RS).

A estrutura organizacional da Alpha é formada pelos sócios, estagiários, consultores e assessores jurídico e contábil. Como norteadores estratégicos, a empresa possui missão, visão e valores bem definidos. Sua missão é 'Conceber soluções em gestão empresarial com foco nas reais demandas das organizações, agregando valor aos negócios dos clientes'. A visão é 'Ser referência no mercado pela excelência nos serviços prestados e resultados proporcionados aos clientes em sua área de atuação'. E como valores inerentes à empresa têm-se a ética, a integridade, o comprometimento, o respeito e o aprendizado contínuo.

A empresa conta com oito serviços distintos de consultoria, sendo divididos entre as áreas de Pessoas, Pesquisas e Marketing: cliente oculto, gestão de relacionamento com clientes, treinamentos in company, pesquisa de clima organizacional, pesquisa de mercado, pesquisa de satisfação, plano de marketing e plano de negócios. Além de consultorias, a empresa oferece serviços de capacitações trabalhadas nos formatos de palestras, cursos ou workshops. Alguns exemplos de assuntos estudados são elaboração de 
artigos científicos, análise de dados quantitativos e qualitativos; inglês para intercâmbios e para negócios, software SPSS, Excel, AutoCAD, comunicação e oratória, resoluções de questões e dicas para o Teste ANPAD, entre outros.

\section{METODOLOGIA}

Nesta seção, é apresentado o método que conduziu ao desenvolvimento deste artigo, estando estruturado em delineamento da pesquisa, coleta de dados, análise de dados e limitações do método. Este trabalho desenvolveu-se como um estudo de caso, em função da ênfase do estudo em uma unidade em particular, e classifica-se como uma pesquisa de natureza descritiva com abordagem metodológica qualitativa.

Para Sampieri et al. (2013), os estudos descritivos medem, avaliam ou coletam dados sobre diversos aspectos, dimensões ou componentes do fenômeno a ser pesquisado. Em relação à pesquisa qualitativa, de acordo com Godoy (1995), esta não procura enumerar ou medir os eventos estudados, nem utiliza ferramentas estatísticas na análise dos dados. Além disso, este tipo de pesquisa abrange a obtenção de dados através do contato direto do pesquisador com a situação que está sendo estudada.

Acerca dos procedimentos técnicos, a coleta de dados realizou-se através do estudo de caso. Para Gil (2010), o estudo de caso "consiste no estudo profundo e exaustivo de um ou poucos objetos, de maneira que permita seu amplo e detalhado conhecimento". Segundo Yin (2010), os dados para os estudos de caso podem vir de fontes como documentos (pesquisa documental), registros em arquivo, entrevistas, observação direta, observação participante e artefatos físicos.

\section{Técnica de coleta de dados}

Como técnicas de coleta de dados, foram utilizadas a revisão bibliográfica, a pesquisa documental, a entrevista semiestruturada e a observação participante. Este estudo iniciou-se com o levantamento de referencial bibliográfico acerca dos temas administração estratégica e Balanced Scorecard. Gil (2010) define algumas etapas para este tipo de pesquisa: escolha do tema; levantamento bibliográfico preliminar; formulação do problema; elaboração do plano provisório de assunto; busca das fontes; leitura do material; fichamento; organização lógica do assunto; e redação do texto.

Logo, realizou-se uma pesquisa documental por meio de documentos e materiais disponibilizados pelos gestores da empresa. De acordo com Lakatos et al. (2010), a pesquisa documental consiste em coletar os dados que estão restritos a documentos, sejam estes escritos ou não, podendo ser realizado no momento em que o fato ocorre, ou depois. Alguns exemplos de fonte são: relatórios, propostas, planos, etc.

Após, foram realizadas entrevistas semiestruturadas com os proprietários da Alpha. Para Boni et al. (2005), a entrevista semiestruturada combina perguntas abertas e fechadas e o informante tem a possibilidade de discorrer sobre o tema proposto. O entrevistador deve seguir um conjunto de questões previamente definidas, mas o contexto se assemelha a uma conversa informal. Também foi utilizada a observação participante como técnica de coleta de dados, na qual, segundo Lakatos et al. (2010), o 
pesquisador se incorpora ao grupo, confunde-se com ele, ficando tão próximo quanto um membro do grupo que está estudando e participa das atividades normais deste. Após a coleta de dados a partir de entrevistas com os proprietários, observação participante, revisão bibliográfica e pesquisa documental, realizou-se a análise de dados, compilando as informações em quadros, tabelas e figuras.

\section{RESULTADOS E DISCUSSÃO}

\section{Definição dos objetivos}

Com base no modelo de negócios da Alpha, na sua missão, visão e valores já estabelecidos pela empresa, cabe formular objetivos que a mesma deseja alcançar em um período de tempo, bem como as estratégias e ações necessárias para alcançá-los. Destaca-se que, para a formulação dos objetivos, utilizaramse as perspectivas delineadas por Kaplan et al. (1992): financeiro, cliente, processos internos e aprendizado e crescimento, dando suporte para a criação do mapa estratégico.

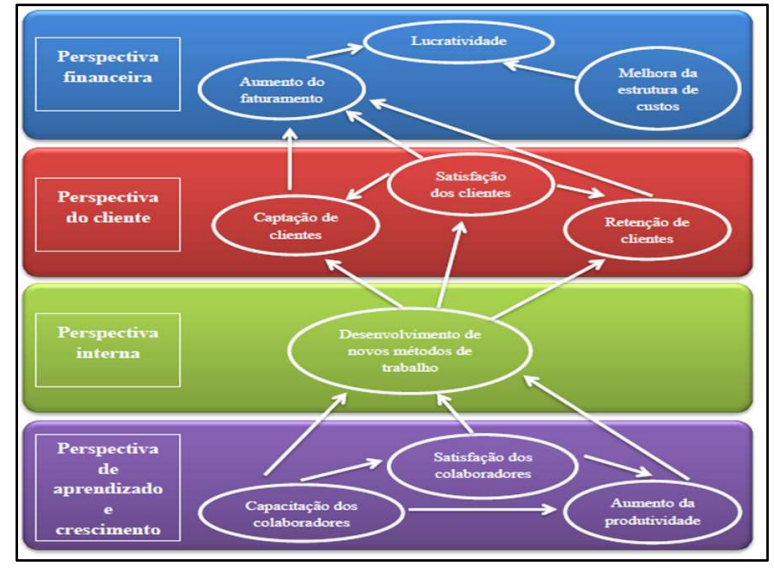

Figura 4: Mapa estratégico da empresa.

Assim, definiram-se como objetivos: perspectiva financeira: melhora da estrutura de custos, aumento do faturamento e lucratividade, tendo em vista que a empresa quer se tornar mais competitiva em relação a seus concorrentes; perspectiva do cliente: captação de clientes, satisfação de clientes e retenção de clientes, considerando que a baixa conversão de clientes é uma fraqueza da empresa; perspectiva interna: desenvolvimento de novos métodos de trabalho, pois, dessa forma, a empresa será capaz de aprimorar-se continuamente; e perspectiva de aprendizado e crescimento: capacitação dos colaboradores, satisfação dos colaboradores e aumento da produtividade, a fim de que a equipe esteja constantemente qualificada e apresente bons resultados. A figura 4 ilustra o mapa estratégico, elaborado a partir das definições dos objetivos estratégicos.

\section{Definição das estratégias e ações}

Com base nos objetivos definidos, a partir da metodologia do BSC, são formuladas as estratégias e ações a fim de alcançar cada um deles (quadro 1). Após a formulação das estratégias e ações, é necessária a sua implementação na empresa e, na sequência, o controle e a avaliação dos resultados, os quais serão abordados. 
Quadro 1: Estratégias e ações definidas com base nas perspectivas e objetivos.

\begin{tabular}{|c|c|c|c|}
\hline Perspectivas & Objetivos & Estratégias & Ações \\
\hline \multirow{3}{*}{ Financeiro } & $\begin{array}{l}\text { Aumentar } \\
\text { faturamento }\end{array}$ & \multirow{2}{*}{$\begin{array}{l}\text { Ampliação das vendas. } \\
\text { Melhorar o controle interno. }\end{array}$} & \multirow{2}{*}{$\begin{array}{l}\text { Realizar mais ações de marketing, em } \\
\text { conjunto com a estratégia de "aumentar as } \\
\text { campanhas de marketing"; } \\
\text { elaborar relatórios com os resultados } \\
\text { financeiros. }\end{array}$} \\
\hline & $\begin{array}{l}\text { Aumentar } \\
\text { lucratividade }\end{array}$ & & \\
\hline & $\begin{array}{l}\text { Melhorar a } \\
\text { estrutura de custos }\end{array}$ & $\begin{array}{l}\text { Planilha de mensuração da } \\
\text { margem de contribuição e do } \\
\text { ponto de equilíbrio. }\end{array}$ & Criar planilha \\
\hline \multirow{6}{*}{ Cliente } & \multirow[t]{2}{*}{$\begin{array}{l}\text { Aumentar a } \\
\text { captação de clientes }\end{array}$} & $\begin{array}{l}\text { Melhorar a prospecção de clientes } \\
\text { (buscar novos clientes). }\end{array}$ & $\begin{array}{l}\text { Aumentar a divulgação dos serviços nas redes } \\
\text { sociais; } \\
\text { publicar vídeos de clientes satisfeitos; } \\
\text { participar de eventos na comunidade } \\
\text { acadêmica e empresarial; } \\
\text { realizar palestras em instituições; } \\
\text { firmar parceria com empresas de áreas afins; }\end{array}$ \\
\hline & & $\begin{array}{l}\text { Aumentar a produtividade dos } \\
\text { colaboradores. }\end{array}$ & $\begin{array}{l}\text { Oferecer cursos de aperfeiçoamento; } \\
\text { realizar planejamento para captação de } \\
\text { clientes. }\end{array}$ \\
\hline & Retenção de clientes & $\begin{array}{l}\text { Buscar a manutenção de } \\
\text { relacionamentos duradouros e } \\
\text { rentáveis. }\end{array}$ & $\begin{array}{l}\text { Realizar visitas, ligações e contatos } \\
\text { permanentes. }\end{array}$ \\
\hline & \multirow{3}{*}{$\begin{array}{l}\text { Satisfação dos } \\
\text { clientes }\end{array}$} & Atendimento diferenciado & $\begin{array}{l}\text { Prezar pela qualidade no atendimento, } \\
\text { visitando os clientes e mantendo contato. }\end{array}$ \\
\hline & & Facilidades de pagamento & $\begin{array}{l}\text { Oferecer diversas formas de pagamento e } \\
\text { destacá-las na apresentação das propostas. }\end{array}$ \\
\hline & & $\begin{array}{l}\text { Obter feedback a respeito do } \\
\text { desempenho da empresa. }\end{array}$ & Realizar pesquisas de satisfação. \\
\hline $\begin{array}{l}\text { Processos } \\
\text { internos }\end{array}$ & $\begin{array}{l}\text { Novos métodos de } \\
\text { trabalho para as } \\
\text { consultorias } \\
\text { existentes }\end{array}$ & $\begin{array}{l}\text { Desenvolver novos métodos de } \\
\text { trabalho de acordo com a } \\
\text { demanda dos clientes. }\end{array}$ & $\begin{array}{l}\text { Buscar capacitação constante e estudar novas } \\
\text { metodologias, atualização. }\end{array}$ \\
\hline \multirow{4}{*}{$\begin{array}{l}\text { Aprendizado e } \\
\text { crescimento }\end{array}$} & $\begin{array}{l}\text { Capacitação dos } \\
\text { colaboradores }\end{array}$ & $\begin{array}{l}\text { Treinamento para } \\
\text { colaboradores. }\end{array}$ & $\begin{array}{l}\text { Oferecer cursos de aperfeiçoamento na área } \\
\text { de negociação e vendas. }\end{array}$ \\
\hline & $\begin{array}{ll}\begin{array}{l}\text { Satisfação } \\
\text { colaboradores }\end{array} & \text { dos } \\
\end{array}$ & $\begin{array}{l}\text { Obter feedback } \\
\text { colaboradores. }\end{array}$ & Realizar pesquisa de satisfação. \\
\hline & \multirow{2}{*}{$\begin{array}{l}\text { Aumento da } \\
\text { produtividade }\end{array}$} & Capacitação dos colaboradores & $\begin{array}{l}\text { Realizar cursos nas áreas das consultorias, } \\
\text { vendas e negociação. }\end{array}$ \\
\hline & & $\begin{array}{l}\text { Realizar planejamento } \\
\text { captação de clientes. }\end{array}$ & $\begin{array}{l}\text { Estruturar e padronizar o processo de } \\
\text { captação de clientes. }\end{array}$ \\
\hline
\end{tabular}

\section{Controle estratégico: indicadores e planos de ação}

O controle estratégico permite comparar os padrões previamente estabelecidos com os resultados obtidos, assim como mensurar e avaliar o desempenho e o resultado das ações. Nesse sentido, o desempenho organizacional é medido através de um conjunto de indicadores, baseados nos objetivos definidos anteriormente. Portanto, o quadro 2 demonstra os indicadores escolhidos para a empresa Alpha.

Quadro 2: Indicadores de desempenho definidos com base nas perspectivas e objetivos.

\begin{tabular}{|c|l|l|l|}
\hline Perspectivas & \multicolumn{1}{|c|}{ Objetivos } & \multicolumn{1}{c|}{ Indicadores } & \multicolumn{1}{c|}{ Descrição dos Indicadores } \\
\hline \multirow{5}{*}{ Financeiro } & $\begin{array}{l}\text { Aumentar o } \\
\text { faturamento }\end{array}$ & Faturamento & $\begin{array}{l}\text { Indica a evolução do faturamento durante um } \\
\text { determinado período de tempo. }\end{array}$ \\
\cline { 2 - 4 } & $\begin{array}{l}\text { Aumentar a } \\
\text { lucratividade }\end{array}$ & Taxa de lucratividade & $\begin{array}{l}\text { Indica o ganho que a empresa consegue gerar } \\
\text { sobre o trabalho que desenvolve. }\end{array}$ \\
\cline { 2 - 4 } & $\begin{array}{l}\text { Melhorar a quargem de contribuição é a quantia } \\
\text { estrutura de custos }\end{array}$ & $\begin{array}{l}\text { Margem de contribuição e } \\
\text { ponto de equilíbrio }\end{array}$ & $\begin{array}{l}\text { margem dinheiro que sobra do preço de venda de um } \\
\text { produto/serviço. } \\
\text { Já o ponto de equilíbrio é o valor ou quantidade em } \\
\text { que a empresa não tem lucro nem prejuízo. }\end{array}$ \\
\hline
\end{tabular}




\begin{tabular}{|c|c|c|c|}
\hline \multirow[t]{3}{*}{ Cliente } & $\begin{array}{l}\text { Aumentar } \\
\text { captação } \\
\text { clientes }\end{array}$ & $\begin{array}{l}\text { Taxa de captação de clientes } \\
\text { e taxa de conversão de } \\
\text { clientes. } \\
\text { A produtividade é } \\
\text { mensurada na perspectiva } \\
\text { de aprendizado e } \\
\text { crescimento. }\end{array}$ & $\begin{array}{l}\text { Captação: Comparar em um período de tempo } \\
\text { quantos novos clientes foram captados. } \\
\text { Conversão: comparar o número de propostas } \\
\text { aceitas com o número de propostas apresentadas. }\end{array}$ \\
\hline & $\begin{array}{l}\text { Retenção } \\
\text { clientes }\end{array}$ & Taxa de retenção de clientes & $\begin{array}{l}\text { Comparar o número de clientes que voltam a } \\
\text { comprar com o número total de cliente atendidos. }\end{array}$ \\
\hline & $\begin{array}{ll}\begin{array}{l}\text { Satisfação dos } \\
\text { clientes }\end{array} & \text { dos } \\
\end{array}$ & $\begin{array}{l}\text { Índice de satisfação dos } \\
\text { clientes }\end{array}$ & $\begin{array}{l}\text { Através de pesquisas, obter feedback dos clientes } \\
\text { em relações a critérios preestabelecidos. }\end{array}$ \\
\hline Processos internos & $\begin{array}{l}\text { Novos métodos de } \\
\text { trabalho para as } \\
\text { consultorias } \\
\text { existentes }\end{array}$ & $\begin{array}{l}\text { Desenvolvimento de novos } \\
\text { métodos }\end{array}$ & $\begin{array}{l}\text { Acompanhar as melhorias implementadas nos } \\
\text { serviços disponibilizados em um determinado } \\
\text { espaço de tempo. }\end{array}$ \\
\hline \multirow{3}{*}{$\begin{array}{l}\text { Aprendizado e } \\
\text { crescimento }\end{array}$} & $\begin{array}{l}\text { Capacitação dos } \\
\text { colaboradores }\end{array}$ & Horas de treinamento & $\begin{array}{l}\text { Mensurar as horas utilizadas em treinamentos com } \\
\text { os colaboradores. }\end{array}$ \\
\hline & $\begin{array}{l}\text { Satisfação dos } \\
\text { colaboradores }\end{array}$ & Pesquisa de satisfação & $\begin{array}{l}\text { Através de pesquisas, obter feedback dos } \\
\begin{array}{l}\text { colaboradores em relações a critérios } \\
\text { preestabelecidos. }\end{array}\end{array}$ \\
\hline & $\begin{array}{l}\text { Aumento da } \\
\text { produtividade }\end{array}$ & Índice de produtividade & $\begin{array}{l}\text { Comparar o número de propostas aceitas com o } \\
\text { número de propostas apresentadas pelos } \\
\text { colaboradores, individualmente. }\end{array}$ \\
\hline
\end{tabular}

Dentro do controle estratégico, inserem-se os planos de ação, que auxiliam a empresa na execução das ações propostas. A utilização de planos de ação é de suma importância para o desenvolvimento do planejamento estratégico em uma organização, pois contém informações como os objetivos propostos, as estratégias e ações definidas para alcançá-los, os responsáveis pela atividade, o prazo para sua realização e os indicadores que serão utilizados para mensurar e acompanhar a efetividade das propostas.

Diante do estudo realizado e com base no plano de ação de Andrade (2012), apresentado no referencial teórico, bem como nas perspectivas e objetivos do BSC, nas estratégias e ações formuladas e nos indicadores de desempenho definidos anteriormente, foram elaborados os planos de ação para a Alpha (quadro 3). A elaboração destes planos de ação permite à empresa delegar ações, ter definidas as responsabilidades, prazos e resultados de cada ação, controlar as ações periodicamente, tomar decisões rápidas frente a imprevistos, visualizar claramente o andamento das ações do seu plano, entre outros benefícios.

Quadro 3: Planos de ação da Alpha.

\begin{tabular}{|c|c|c|c|c|c|}
\hline \multicolumn{6}{|c|}{ PERSPECTIVA: FINANCEIRA } \\
\hline OBJETIVOS & ESTRATÉGIAS & AÇÕES & RESPONSÁVEL & PRAZO & INDICADORES \\
\hline $\begin{array}{l}\text { Aumentar o } \\
\text { faturamento }\end{array}$ & \multirow[b]{2}{*}{$\begin{array}{l}\text { Ampliação das } \\
\text { vendas } \\
\text { Melhorar o controle } \\
\text { interno }\end{array}$} & \multirow{2}{*}{$\begin{array}{l}\text { Realizar mais ações de } \\
\text { marketing, em conjunto } \\
\text { com a estratégia de } \\
\text { "aumentar as } \\
\text { campanhas de } \\
\text { marketing"; } \\
\text { elaborar relatórios com } \\
\text { os resultados } \\
\text { financeiros. }\end{array}$} & \multirow[b]{2}{*}{ Sócios } & \multirow[b]{2}{*}{ Mensal } & Faturamento \\
\hline $\begin{array}{l}\text { Aumentar a } \\
\text { lucratividade }\end{array}$ & & & & & Taxa de lucratividade \\
\hline $\begin{array}{l}\text { Melhorar a } \\
\text { estrutura de } \\
\text { custos }\end{array}$ & $\begin{array}{c}\text { Planilha de } \\
\text { mensuração da } \\
\text { margem de } \\
\text { contribuição e do } \\
\text { ponto de equilíbrio. }\end{array}$ & Criar planilha & $\begin{array}{l}\text { Responsável } \\
\text { finanças }\end{array}$ & $30 / 07$ & $\begin{array}{c}\text { Margem de } \\
\text { contribuição e ponto } \\
\text { de equilíbrio }\end{array}$ \\
\hline \multicolumn{6}{|c|}{ PERSPECTIVA: CLIENTES } \\
\hline OBJETIVOS & ESTRATÉGIAS & AÇÕES & RESPONSÁVEL & PRAZO & INDICADORES \\
\hline
\end{tabular}


TREVISAN, L. V.; FIALHO, C. B.; CORONEL, D. A.

\begin{tabular}{|c|c|c|c|c|c|}
\hline \multirow[t]{2}{*}{$\begin{array}{l}\text { Aumentar a } \\
\text { captação de } \\
\text { clientes }\end{array}$} & $\begin{array}{l}\text { Melhorar a } \\
\text { prospecção de } \\
\text { clientes (buscar } \\
\text { novos clientes). }\end{array}$ & $\begin{array}{c}\text { Aumentar a divulgação } \\
\text { dos serviços nas redes } \\
\text { sociais; } \\
\text { publicar vídeos de } \\
\text { clientes satisfeitos; } \\
\text { participar de eventos na } \\
\text { comunidade acadêmica } \\
\text { e empresarial; } \\
\text { realizar palestras em } \\
\text { instituições; } \\
\text { firmar parceria com } \\
\text { empresas de áreas afins. }\end{array}$ & Sócios & Mensal & $\begin{array}{l}\text { Taxa de captação de } \\
\text { clientes e taxa de } \\
\text { conversão de } \\
\text { clientes. } \\
\text { A produtividade é } \\
\text { mensurada na } \\
\text { perspectiva de } \\
\text { aprendizado e } \\
\text { crescimento. }\end{array}$ \\
\hline & $\begin{array}{l}\text { Aumentar a } \\
\text { produtividade dos } \\
\text { colaboradores. }\end{array}$ & $\begin{array}{l}\text { Oferecer cursos de } \\
\text { aperfeiçoamento; } \\
\text { realizar planejamento } \\
\text { para captação de } \\
\text { clientes. }\end{array}$ & $\begin{array}{l}\text { Responsável } \\
\text { operações }\end{array}$ & Trimestral & \\
\hline $\begin{array}{l}\text { Retenção de } \\
\text { clientes }\end{array}$ & $\begin{array}{l}\text { Buscar a } \\
\text { manutenção de } \\
\text { relacionamentos } \\
\text { duradouros e } \\
\text { rentáveis. } \\
\end{array}$ & $\begin{array}{c}\text { Realizar visitas, ligações } \\
\text { e contatos } \\
\text { permanentes. }\end{array}$ & Sócios & Mensal & $\begin{array}{c}\text { Taxa de retenção de } \\
\text { clientes }\end{array}$ \\
\hline \multirow{3}{*}{$\begin{array}{l}\text { Satisfação dos } \\
\text { clientes }\end{array}$} & $\begin{array}{l}\text { Atendimento } \\
\text { diferenciado }\end{array}$ & $\begin{array}{l}\text { Prezar pela qualidade no } \\
\text { atendimento, visitando } \\
\text { os clientes e mantendo } \\
\text { contato. }\end{array}$ & Sócios & Permanente & \multirow{3}{*}{$\begin{array}{c}\text { Índice de satisfação } \\
\text { dos clientes }\end{array}$} \\
\hline & $\begin{array}{l}\text { Facilidades de } \\
\text { pagamento }\end{array}$ & $\begin{array}{c}\text { Oferecer diversas } \\
\text { formas de pagamento e } \\
\text { destacá-las na } \\
\text { apresentação das } \\
\text { propostas. }\end{array}$ & Sócios & Permanente & \\
\hline & $\begin{array}{l}\text { Obter feedback a } \\
\text { respeito do } \\
\text { desempenho da } \\
\text { empresa. }\end{array}$ & $\begin{array}{l}\text { Realizar pesquisas de } \\
\text { satisfação. }\end{array}$ & Sócios & $\begin{array}{l}\text { Até } 30 \text { dias } \\
\text { após o } \\
\text { término da } \\
\text { consultoria }\end{array}$ & \\
\hline \multicolumn{6}{|c|}{ PERSPECTIVA: PROCESSOS INTERNOS } \\
\hline OBJETIVOS & ESTRATÉGIAS & AÇÕES & RESPONSÁVEL & PRAZO & INDICADORES \\
\hline $\begin{array}{l}\text { Novos métodos } \\
\text { de trabalho }\end{array}$ & $\begin{array}{c}\text { Desenvolver novos } \\
\text { métodos de acordo } \\
\text { com a demanda dos } \\
\text { clientes. }\end{array}$ & $\begin{array}{c}\text { Buscar capacitação } \\
\text { constante e estudar } \\
\text { novas metodologias, } \\
\text { atualização. } \\
\end{array}$ & Sócios & Permanente & $\begin{array}{l}\text { Desenvolvimento de } \\
\text { novos métodos }\end{array}$ \\
\hline \multicolumn{6}{|c|}{ PERSPECTIVA: APRENDIZADO E CRESCIMENTO } \\
\hline OBJETIVOS & ESTRATÉGIAS & AÇõES & RESPONSÁVEL & PRAZO & INDICADORES \\
\hline $\begin{array}{l}\text { Capacitação } \\
\text { dos } \\
\text { colaboradores }\end{array}$ & $\begin{array}{l}\text { Treinamento para os } \\
\text { colaboradores }\end{array}$ & $\begin{array}{c}\text { Oferecer cursos de } \\
\text { aperfeiçoamento na } \\
\text { área de negociação e } \\
\text { vendas. }\end{array}$ & $\begin{array}{l}\text { Responsável } \\
\text { operações }\end{array}$ & Trimestral & $\begin{array}{l}\text { Horas de } \\
\text { treinamento }\end{array}$ \\
\hline $\begin{array}{l}\text { Satisfação dos } \\
\text { colaboradores }\end{array}$ & $\begin{array}{c}\text { Obter feedback dos } \\
\text { colaboradores. }\end{array}$ & $\begin{array}{l}\text { Realizar pesquisa de } \\
\text { satisfação. }\end{array}$ & Sócios & Semestral & $\begin{array}{l}\text { Pesquisa de } \\
\text { satisfação }\end{array}$ \\
\hline \multirow{2}{*}{$\begin{array}{l}\text { Aumento da } \\
\text { produtividade }\end{array}$} & Capacitação & $\begin{array}{c}\text { Realizar cursos nas áreas } \\
\text { das consultorias, vendas } \\
\text { e negociação. }\end{array}$ & $\begin{array}{l}\text { Responsável } \\
\text { operações }\end{array}$ & Trimestral & \multirow{2}{*}{$\begin{array}{l}\text { Índice de } \\
\text { produtividade }\end{array}$} \\
\hline & $\begin{array}{c}\text { Realizar } \\
\text { planejamento para } \\
\text { captação de clientes. }\end{array}$ & $\begin{array}{c}\text { Estruturar e padronizar } \\
\text { o processo de captação } \\
\text { de clientes. }\end{array}$ & Sócios & Trimestral & \\
\hline
\end{tabular}

\section{CONCLUSÕES}

A administração estratégica, por meio de seus processos e ferramentas, permite a uma organização uma série de benefícios, entre elas a adaptação contínua às exigências do mercado. Neste contexto, através da análise da empresa Alpha, a qual, em função da expansão de mercado e reestruturação de alguns serviços, vem experimentando uma necessidade de reformular algumas áreas e atividades, constataram-se necessidades de melhorias em alguns processos estratégicos, como formulação de estratégias e controle 
estratégico. Assim, com a intenção de auxiliar a Alpha, o objetivo principal deste estudo foi a implantação da ferramenta de gestão Balanced Scorecard (BSC) na empresa.

A partir das cinco perspectivas do BSC, foram elaborados os objetivos estratégicos, o mapa estratégico, as estratégias e ações, os indicadores de desempenho e os planos de ação para a Alpha. Assim, o estudo mostrou uma proposta de implantação de uma ferramenta da administração estratégica em uma organização e a relevância da utilização deste tipo de prática. Além disso, enfatizou a importância da formulação de objetivos, estratégias, ações, de um sistema de controle e avaliação contínua, a fim de comparar os resultados alcançados e os previstos.

No que tange às limitações do estudo, destaca-se o curto período de duração da pesquisa, o que, de certa forma, influenciou uma segunda limitação. Ela se relaciona ao objetivo geral do trabalho, o qual tratava da implantação da ferramenta BSC na empresa, pois envolve, além da definição e estruturação dos indicadores de desempenho, a mensuração dos indicadores por meio de coleta de dados. Assim, esse objetivo precisou ser revisto, já que a empresa não dispunha dos dados necessários em relação a todos os indicadores propostos, e isso pode ser atribuído ao fato de este processo de controle e avaliação ser novo à organização, ainda não dispondo de um sistema de informação capaz de disponibilizar tais dados.

Como sugestão para estudos futuros, salienta-se a continuidade da proposta iniciada neste trabalho, com o objetivo de implantar o BSC na empresa estudada e mensurar os resultados obtidos. Além disso, sugere-se a replicação do estudo em outras empresas, e, até mesmo, um aprofundamento, considerando outras variáveis e itens não abordados neste trabalho.

\section{REFERÊNCIAS}

AAKER, D. A.. Administração estratégica de mercado. 7 ed. Porto Alegre: Bookman, 2007.

ALVAREZ, M. E. B.. Estratégia da Visão à Ação. São Paulo: Atlas, 2011

ANDRADE, A. R.. Planejamento estratégico: formulação, implementação e controle. São Paulo: Atlas, 2012.

BARNEY, J. B.. Firm resources and sustained competitive advantage. Journal of Management, v.17, n.1, p.99-120, 1991.

BONI, V.; QUARESMA, S. J.. Aprendendo a entrevistar: como fazer entrevistas em Ciências Sociais. Revista Eletrônica dos Pós-Graduandos em Sociologia Política da UFSC, Florianópolis, v.2, n.1, p.68-80, 2005.

CARNEIRO, J. M. T.. Mensuração do desempenho organizacional: questões conceituais e metodológicas. In: GUTIERREZ, M.; BERTRAND, H.. Estudos em Negócios IV. Rio de Janeiro: Mauad, 2005. p.145-176.

CERTO, S. C; PETER, J. P.. Administração estratégica: planejamento e implantação de estratégias. 3 ed. São Paulo: Pearson Education do Brasil, 2010.

COSTA, E. A.. Gestão Estratégica: da empresa que temos para a empresa que queremos. 2 ed. São Paulo: Saraiva, 2007.
GIL, A. C.. Como elaborar projetos de pesquisa. 5 ed. São Paulo: Atlas, 2010.

GODOY, A. S.. Introdução à pesquisa qualitativa e suas possibilidades. Revista de Administração de Empresas, São Paulo, v.35, n.2, p.57-63, 1995.

IGARASHI, D. C. C.; IGARASHI, W.; FERREIRA, E. S.; HERCOS JÚNIOR, J. B.. Implantação do mapa estratégico e painel de desempenho em uma empresa comercial da região oeste do Paraná. Revista de Informação Contábil, Recife, v.4, n.4, p.23-41, 2010.

KAPLAN, R. S.; NORTON, D. P.. A estratégia em ação: balanced scorecard. 14 ed. Rio de Janeiro: Campus, 1997.

KAPLAN, R. S.; NORTON, D. P.. Mapas Estratégicos: Convertendo ativos intangíveis em resultados tangíveis. 7 ed. Rio de Janeiro: Elsevier, 2004.

KAPLAN, R. S.; NORTON, D. P.. The balanced scorecardmeasures that drive performance. Harvard Business Review, v.70, n.1, 1992.

LAKATOS, E. M.; MARCONI, M. A.. Fundamentos de Metodologia Científica. 7 ed. São Paulo: Atlas, 2010.

MINTZBERG, H.. Ascensão e queda do planejamento estratégico. Porto Alegre: Bookman, 2004. 
OLIVEIRA, D. P. R.. Planejamento estratégico: conceitos, metodologia e práticas. 30 ed. São Paulo: Atlas, 2012.

PRIETO, V. C.; Pereira, F. L. A.; CARVALHO, M. M.; LAURINDO, F. J. B.. Fatores Críticos na Implementação do Balanced Scorecard. Gestão \& Produção, v.13, n.1, p.81-92, 2006.

QUEIROZ, R. T.; LOBOSCO, A.; ALMEIDA, M. I. R.; MACCARI, E. A.. A inserção da ferramenta Balanced Scorecard no planejamento estratégico de uma empresa em crescimento: um estudo de caso na empresa Metadil Indústria e Comércio Metalúrgica Ltda. Future Studies Research Journal, São Paulo, v.7, n.1, p.81-112, 2015.

SAMPIERI, R. H.; COLLADO, C. F.; LUCIO, M. P. B..

Metodologia de pesquisa. 5 ed. Porto Alegre: Penso, 2013.

TAVARES, M. C.. Gestão Estratégica. 2 ed. São Paulo: Atlas, 2007.

YIN, R. K.. Estudo de caso: planejamento e métodos. 4 ed. Porto Alegre: Bookman, 2010.

A CBPC - Companhia Brasileira de Produção Científica (CNPJ: 11.221.422/0001-03) detém os direitos materiais desta publicação. Os direitos referem-se à publicação do trabalho em qualquer parte do mundo, incluindo os direitos às renovações, expansões e disseminações da contribuição, bem como outros direitos subsidiários. Todos os trabalhos publicados eletronicamente poderão posteriormente ser publicados em coletâneas impressas sob coordenação da Sustenere Publishing, da Companhia Brasileira de Produção Científica e seus parceiros autorizados. Os (as) autores (as) preservam os direitos autorais, mas não têm permissão para a publicação da contribuição em outro meio, impresso ou digital, em português ou em tradução. 